\title{
Ethical Issues on Utilization of AI, Robotics and Automation Technologies
}

ISSN: 2311-8636 (Print)

ISSN: 2312-2021 (Online)

Licensed:

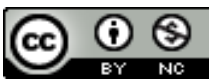

Source of Support: Nil

No Conflict of Interest: Declared

* Correspondence Email:

drwahid.sob@aust.edu

\section{Wahiduzzaman Khan ${ }^{1 *}$, Takudzwa Fadziso ${ }^{2}$}

${ }^{1}$ Associate Professor of Marketing, School of Business, Ahsanullah University of Science and Technology, Dhaka, BANGLADESH

${ }^{2}$ Institute of Lifelong Learning and Development Studies, Chinhoyi University of Technology, ZIMBABWE

\section{ABSTRACT}

The fast technological advancements in machine intelligence and automation may also arrive with risks and some negative effects on employees, firms, and society at large. Currently, both end-users, scientists, and practitioners have acknowledged the need for machine assistance and also welcome consideration for a robust ethical strategy that will allow a safe application and usage of improved technologies. Artificial Intelligence related ethics has been presented and considered from various standpoints and views. This paper furthers on the subject. Potential ethical issues are envisaged in the area of machine end-user perceptions, privacy, accountability, and the robot/ human rights, design of ethical machines, and technological singularity. It, therefore, possesses the question. What are the current ethical issues with the use of machines? The study adopted a quantitative and qualitative approach to drawing conclusions from the thematic and descriptive analysis. The result shows that majority of the respondents were males 46 (65.7\%) while $24(34.3 \%)$ were females. They are mainly literates/ Majority $49(70 \%)$ are from the private firm and come majorly from the Asian continent. The majority of the respondent's view that ethical consideration is necessary for machine and automation design, the machine-human relationship should be improved. Their privacy should be instituted while they consider technology singularity as a severe issue and desire the creation of ethical machines. Following this result, the study documents policy recommendations.

Keywords: Artificial Intelligence, technological singularity, automation, robotics, privacy

\section{INTRODUCTION}

Artificial intelligence enhanced technologies have been applied in various of contexts and industries such as labour market, healthcare, research and design, education, commerce, military and security, and transport and many more (Luxton 2014; Lutz and Tamò 2015). Mosche Verdi, a US scientist predicts that by 2045, a lot of machines will have the capacity to take up task that were previously done by man (Reeves, 2016). However, these fast technological advancements may also arrive with risks and some negative effects on employees, firms and the society at large (Belloni et al 2015; Zeng 2015; Reeves, 2016; Donepudi, 2015). Currently both end-users, scientists and practitioners have 
acknowledged the need machine assistance and also welcome consideration for robust ethical strategy which will allow a safe application and usage of improved technologies. Artificial Intelligence related ethics has been presented and considered from various standpoint and views.

This paper incorporate discussion from psychology, philosophy, politics, anthropology, law, computer science, economics, various areas of advanced technology, and science fiction (Zeng 2015; Belloni et al., 2015; Torras, 2015). We are beginning to witness new terms and specialization including AI ethics, machine ethics, roboethics, artificial moral agents, cyber ethics, robot rights, robotic privacy (Luxton 2014; Donepudi, 2020; Lutz and Tamò 2015; Ashrafian, 2015; Reeves, 2016; Bryson, 2016). These specialty seems to describe events and situations with anticipated future impacts as it relates to technologies. They are rather speculative and visionary instead of presenting and drawing themes from real-life situations (Michelfelder, 2011; Torras, 2015; Zeng, 2015). Potential ethical issues can be envisaged in Machine end- user perceptions, privacy, accountability, and the robot/ human rights, design of ethical machines and technological singularity. To this end, the current study examines the ethical issues on utilization of AI, robotics and automation technologies. It therefore possesses the question. What are the current ethical issues on the use of machines?

\section{Objective of the study}

The objective of this study is to examine the ethical issues on utilization of AI, robotics and automation technologies. What are the health and safety issues that should be considered in firms? The study examines the potential ethical issues in the following areas; Machine end- user perceptions, privacy, accountability, and the robot and human rights, design of ethical machines and technological singularity. The rest of the paper is arranged as follows; section 2 present literature review, section 3 gives the methodology. In section 4 , the result of the study is presented while section 5 documents the conclusion and recommendation.

\section{Ethical IsSUes on Utilization of Al ANd Automation TeChNologies}

\section{The Human -Machine Relationship}

Luxton (2014) proposes a number of ethical consideration associated to artificial intelligence care providers (AICPs) in the mental health and in the care professions including nursing, medicine, education, social work, and ministry) in general. Artificial intelligence care providers exist in different forms and use AI in various ways. For example, AICPs may be virtual simulations, could be a social robot either non-humanoid or humanoid. They can also act as a non-embodied system; for instance, audio simulations. At present, a lot of AICPs and caring machines are fabricated to capture behaviors and detect emotional signals. Others are designed to simulate emotions and be empathetic as well hence, the line between machines and humans is becoming thinner and in many extreme circumstances can cause Turing deceptions. Turing deceptions refers to the inability of a human to know if they are communicating with a machine. There could be a major ethical issue, mainly in cases of vulnerable people; for instance, patients and children.

Luxton (2014) reported that even while patients who communicated with an Artificial Intelligent-simulated psychotherapist knew and understood that they were mere software, they still behaved as though they were communicating with real therapist. In general, 
similar reports have been documented in relation to the surging application of robotic nannies and companion robots (Torras, 2015; Frude and Jandrić, 2015; Reeves, 2016). In other that humans shield themselves from the potential negative effects of enhanced social robots on their mental health, they base their emotional responses to an Artificial Intelligence on its anthropomorphism i.e ability to look like human. The uncanny valley' effect explains it better i.e that is, the more a robot tends to be like human, the less likely it is to derive positive response in humans) (Torras, 2015).

\section{Privacy and Robots/ Human Rights}

On the whole, Artificial Intelligence systems get numerous feedbacks from human users. This connote a potential risk of breaking the rules that governs personal data protection rules, and in a broader perspective, human trust and privacy (Luxton 2014; Zeng 2015). For example, some innovations that are created for healthcare including psychological identification system which is use in mental health care, some can also be applied in other uses aside its originally intended purpose; for instance; with prisoner interrogation. More so, there is also a likelihood that the information gathered with intelligent machines are utilized by firms and governments in ways and manners not intended. For instance, some present Artificial Intelligent systems are applied to monitor and track phone calls. Aside from the caring professionals, the negative implications extend into other spheres of life including commerce and banking.

The possibility of harvesting large amounts of public data without permission from the users which is a major ethical consideration. More so, there is yet the concern of threats on the right of a majority of certain groups of people. This, it does by initiating a marked change in the labor market and reducing the number of jobs which are available to them. This imply increase in unemployment rates and widening of the inequality gap (Zeng, 2015) while in other instances, machines substitute humans. Metzler et al. (2016) opines that designing human-like assistance machines is neither cost-effective nor desirable. Metzler et al. (2016) posed a question that if the essence of AI systems is to do just some tasks and enable nurses more time to care for patients, is it then necessary to create companion machines that could take on the caring role which humans do?

At the moment, the emerging concerns of robot rights is discussed and advanced more by media than the academia. The main discus is that, as animals, robots should be thought as having rights (Zeng 2015). However, this would depend largely on how they are treated. Are robots treated as though they are beings? Bryson (2016) documents that the potential benefits and costs which both humans and machines possess should form the basis for considering a machine as a moral subject. Bostrom and Yudkowsky, (2011) provides two conditions that is related with high intelligence and associates them to moral status: this include; sapience- self responsibility and self-awareness and sentience - the tendency to suffer and feel.

The general believe is that animals are sentient, however, the humans possess. In the same manner, an Artificial Intelligence system can be said to be possess some moral connotation if, for example, it does feel pain. It follows therefore that if it is considered inappropriate to cause pain to animals, hurting a machine which is deemed intelligent shouldn't be the case. Following this presumptions, if an Artificial Intelligent enhanced system also possess conscience, then it would gain some moral status as though it were humans. However, Zeng (2015) reports that although the present day intelligent machines do not possess moral status, it is still essential to safeguard their rights. Zeng (2015) suggests that those who abuse robots are potentially likely to abuse humans and animals. 


\section{Technological singularity}

There is speculation over concerns of the near future events where Artificial Intelligent systems will be more intelligent, and perhaps even able to comprehend their own sequence and develop successors who are even more intelligent. Eventually, in future, machines can become 'super intelligent', and in some case, more intelligent than the humans (Bostrom and Yudkowsky, 2011; Excell and Earnshaw, 2015). For example, artificial intelligence could publish academic papers, patents that are considered outstanding or even earn some money as a stakeholder in the stock market. Furthermore, machines that are super intelligent able to self-adjust their goal mechanism, implying that they would possess a level of autonomy. While present Artificial Intelligent technologies are not too intelligent to outperformed humans, many scientists are of the view that there is the danger of not being able to control machines. For instance; drones that are exceptionally intelligent could become lethal in the future (Russell et al., 2015; Kinne and Stojanov, 2014).

\section{Design of Ethical machines}

A lot of available Artificial Intelligent ethics associated literature presents the design and prototypes of machines that possess moral status. Roboethics is an upcoming field of Artificial Intelligence ethics that is concerned with how artificial intelligence behaves. More particularly, the phrase 'artificial intelligent agents' connotes Artificial Intelligence systems that apply ethical behaviors when with humans and with other machines (Luxton 2014). This issue is complex. Its complexity is seen in the several of attempts to present models and outlines for designing machines that are ethical. For example, Belloni et al. (2015) outlined the importance of implementing ethical machine behaviors that differs in contexts and put forward a conflict controlled framework for coping and responding to ethical conflicts in agents that are autonomous. Belloni et al. (2015) showed the potential ethical conflicts by illustrating four situations that are associated with a car that is autonomous, a 'lying' Artificial Intelligence personal assistant, a military robot, and an AI system which monitors patients. Dogan et al. (2016) also put forward the potential testing ethical principles in dilemma for vehicles that are automated vehicle. Lutz and Tamò (2015) studied the emerging areas of robotic privacy and documented the role of code as a principal governing index of robots. On the whole, a lot of arguments centers on designing algorithms for artificial intelligence as well as more accepted approaches in forecasting potential risks and creating moral or a more human-like machines. Questions exist on whether morality of machines is same as that of humans or more (Bryson, 2016). This yet another question that has been left open to investigation.

\section{Accountability}

Luxton (2014) stresses the need for competency levels of the AICPs' users. Luxton (2014) suggest that this it will avoid putting the lives of patients at risk. This describes issues of ethics and the designs of intelligent machines. The surging complexity of Artificial Intelligent systems creates even greater difficulty in the areas of interpreting and predicting the behavior of machine and therefore connotes a greater risk to the security of patients and other end users. More so, with the presence of autonomous machines' roles, boundaries that exist between humans and machines are becoming unclear. In the near future, concerns are that they will be impossible to control (Bostrom and Yudkowsky, 2011; Luxton 2014; Zeng 2015). Mores so, when there is a large numbers of people involved in the creation, building and application of intelligent machines, ambiguity sets 
in as to who is responsible. For instance, in this context, moves beyond assisting professions, to the inclusion of situations bordering on the use of autonomous vehicles, banking and commerce, and in autonomous weapon systems (AWS) (Zeng 2015; Dogan et al., 2016).

Currently, both practitioners and scientists have debates vigorously on who to call, and when to give feedback or responsible, for the negative effects of use of intelligent machines. Johnson (2015) outlined and noted the 'responsibility gap. According to Johnson (2015). Should a person and/or machines be held responsible? Johnson (2015) possess the question on the fairness and attributions of responsibility. Again, this is a question that borders on the person in charge - the human using the machine or the machine? For example, should a human or designer take responsibility for the actions and inactions of a machine that is majorly more intelligent than they are? Bryson (2016) responded to this question, by showing that because humans possess the control over the make of the robots, they should take some responsibility for them. She reported further, that 'making AI agents is intentional. The choice of avoiding would be the most ethical option (Bryson, 2016).

\section{From guidelines to policymaking}

Initial attempts to describe and regulate AI-associated ethics may show the future prospect of this emerging specialty (Zeng, 2015). Recent study (Ashrafian, 2015) stresses that most works in this field are centered only on human-robot associations while the potential ethical issues of robots are often times neglected. Ashrafian outlined a new law for robotic- as well as artificial intelligence to artificial intelligence' (AIonAI). Moving from guidelines to policies, present day literature gives some examples of initial efforts to design AI associated policy making and legal frameworks. Zeng (2015) presented that available legislation imply mostly to technologies that are low-tech, while setting aside and not regulating the advanced AI systems (Donepudi, 2018a) mentions that the policies and legal approaches to Artificial Intelligence ethics are merely reactionary- made to react to negative actions. It should be holistic; made to be preventive of negative actions). According to Donepudi (2018b) the issues related to safety, accountability, dignity, and privacy have been handled without considerations to the socio-technical make and form of automation. Owing to the importance of legislation as regards robotics, the EU carried out a study on the subject in 2017. The led down set of legislation that is aimed at allowing the EU 'to completely exploit the economic advantage of artificial intelligence and robotics while guaranteeing an appreciable level of security and security' (EU, 2017). This piece of legislation was intended to be wide and, covering issues including safety, liability, and variations in labor markets.

\section{Health AND Safety IsSUES}

\section{Risk policies and management with regards the use of new technology}

Risk analyses should be done by firms before their technologies are put to use in order to safeguard employees while they working with the robots. More so, the Machinery instructional guide sets an acceptable standard that every machine must meet. Inclusive with other guides, such Directive is provided for a producer's risk evaluation for any machine. The terminology machinery is described as: an assembly, is intended to fit into a drive system rather than directly using animal or human energy, consisting of parts that are linked together. Hence robots are called machinery' for the reasons of the directive they provide. Machinery should not be used in operation not until a safety notes or 
discussion with regards to the employees and the workplace of the employee has made known. More so, policies that regulate the use of the system should be enacted. The potential risk which may arise with the machines occasioned by discrepancies should be included by the producers in their risk assessment.

\section{Application of robots - safety issues}

Aside from production faults, all other faults associated with software should form part of the subject for discussion as potential threats to safety associated to autonomous machines and assistant robots. Furthermore, risks that are unforeseen can be envisaged to come up at any time. A clear definition should be told between the uncertainties bordering on the actual end product and the negative implication for the humans who are working with the robots. It will be of the essence to train workers in both situations. Humans must develop their confidence in the use of the machines. However, they should not depend on it blindly.

\section{Employees' need to be watchful - new risks due to new technology}

When a system is automated, in the firm, it gives rise to a number of safety issues that can lead to accident at work. This is because when an automatic process is set in motion, it becomes difficult to terminate when fault arises. In most cases, even while the procedure is interrupted, totally dealing the risk cannot still be guaranteed. New risk that were heard off or documented by the operators or manufacturers may arise owing to uncontrolled interruption of a procedures. Because most accidents which arise at work are due to lack of synergy between human and the machine or improper usage, it is important to meet national and global safety standards. Effective workplace, health and safety is defined by routine risk evaluation, training of first aid givers, and regular worker. There is need to consult with the experts from each sector to document preventive measures and avoid some hazardous substances which connote risk to the workplace. This should be done by way of policies, the content of such policies must reflect the individual situations and conditions of the local site. Officers, supervisors must regularly monitor the plant. Stiff penalties must be sanctioned to firms that disobey safety. Best practices and ethics should be the order. Individual risks should be responded to and uniquely to reflect the needs of such issues irrespective the source of such risk, whether from intelligent machines, work environment, or human.

\section{Need for health and safety regulations to keep up with technological progress}

In order to engage productively in the workplace with humans and safe production with assistance robots' insurance and, safety law and standards should usually be adapted to the present condition of the technology. Speculative facts, from the pessimistic naysayer or those from positive techno-centric are merely what we have on ground - without concrete facts we cannot be certain of our position, let alone forecast the future

\section{Methodology}

\section{Sources of Data}

The primary sources of data by means of questionnaire and secondary data collection by means of literature review are the major sources of data for this study. The various literature bordering on ethical considerations of machines and automation are done. The survey questionnaire adopted for the study consisted of about two sections. Section A reflects the social status of the participants. Some of the information collected include 
nationality, sex, and age. In section B, the participants were engaged on some ethical issues concerning automation. The statements contained in the questionnaires are modified to match the objective of the subject. All the questionnaire was distributed online to participants.

\section{Research Participants}

The current research seeks to understand the Ethical issues on utilization of AI, robotics and automation technologies. A properly designed research tool was tribute on different online platforms including Instagram, WhatsApp, Facebook and Twitter. A vast majority of participants were then contacted within a duration of the study. The consent of the participants on these platforms, were sought and served with questionnaires. About 50 participants completed and successfully returned the questionnaires.

\section{Technique and Data Analysis}

The method adopted in this study is descriptive statistics and a thematic synthesis of literature. In the first place, the mean, frequencies, graphs and proportions are some of the descriptive statistics used. The author selected a sizable proportions of publications bordering on the subject, excluding those that were deemed as irrelevant to the focus. The thematic approach was done in two stages. In the first stage, a summary for each journal read was done and the information gathered recorded. Next, each source was coded with inscription identifying major themes. Information on the summaries were source, the research technique which was used, the result and limitations. In the second stage of the thematic analysis involved production of a textual analysis of the data as it concerns the focal questions. In relation to the kind of sources used, peer-reviewed journals, publication and conference papers formed the bulk of the source. The peer-reviewed papers consisted of about $62 \%$ of the adopted source. Conference papers is about $25 \%$ of the used source, while the remaining $13 \%$ of sourced material being include the working papers. This imply that a greater proportion of the material used are peer reviewed academic journal paper. Owing to the quality of the sources of information used, a certain level of confidence in the findings and conclusion advanced is heightened.

\section{RESULt AND Discussion}

Table 1 shows the distribution of the respondents by demographics. First is sex. Out of the 70 respondents, about $46(65.7 \%)$ were males while $24(34.3 \%)$ were females. Evidently, the males formed the majority of the respondents. For the distribution by education, $5(7.1 \%)$ of the respondents have gone through primary education, $14(20 \%)$ had gotten a high school certificate; $35(50 \%)$ of them have acquired a college degree while only $16(22.9 \%)$ of the respondents have gotten a degree. Evidently, the participants are literates.

Majority $49(70 \%)$ of the respondents are from the private firms while $21(30 \%)$ are from the public firm. Sectorial distribution shows a greater percent of the respondents are from the manufacturing sector $28(40 \%)$, others include ICT $3(4.3 \%)$, Retail $17(24 \%), 8(11.4 \%)$ are from the accounting/ finance sector, while $14(20 \%)$ are from the transportation sector. For the distribution by origin, 21(30\%) of the respondents are Asian, 14(20\%) respondents are Americans, 6(8.6\%) are Europeans; 9(12.9\%) are from North America while $14(20 \%)$ are from South America. 
Table 1: The descriptive statistics of Participants

\begin{tabular}{|c|c|c|}
\hline Variables & Frequency & Percentage (\%) \\
\hline \multicolumn{3}{|l|}{ Gender } \\
\hline Male & 46 & 65.7 \\
\hline Female & 24 & 34.3 \\
\hline Total & 70 & 100 \\
\hline \multicolumn{3}{|l|}{ Education level } \\
\hline Primary & 5 & 7.1 \\
\hline High school & 14 & 20.0 \\
\hline College & 35 & 50.0 \\
\hline Others & 16 & 22.9 \\
\hline Total & 70 & 100 \\
\hline \multicolumn{3}{|l|}{ Firm type } \\
\hline Private firms & 49 & 70.0 \\
\hline Public firms & 21 & 30.0 \\
\hline Total & 70 & 100 \\
\hline \multicolumn{3}{|l|}{ Sector } \\
\hline ICT & 3 & 4.3 .0 \\
\hline Retail & 17 & 24.0 \\
\hline Accounting/ Finance & 8 & 11.4 \\
\hline Transportation & 14 & 20.0 \\
\hline Manufacturing & 28 & 40.0 \\
\hline Total & 50 & 100 \\
\hline \multicolumn{3}{|l|}{ Origin } \\
\hline Asian & 21 & 30.0 \\
\hline Americans & 14 & 20.0 \\
\hline Europeans & 6 & 8.6 \\
\hline North Americans & 9 & 12.9 \\
\hline South Americans & 14 & 20.0 \\
\hline Others & 6 & 8.6 \\
\hline Total & 50 & 100 \\
\hline
\end{tabular}

Source; Authors computation using SPSS, 2020

The study has respondents from all over the world. With this rich background, expectations are that the study will give us the right perspective on employees and work. The respondents are pulled from various sectors. Evidently, the result from this study will be unique because of industry unique perspective. 
Table 2: Ethical Considerations

\begin{tabular}{|c|c|c|}
\hline Variables & Frequency & Percentage $(\%)$ \\
\hline \multicolumn{3}{|c|}{ Ethical considerations are vital } \\
\hline No & 46 & 65.7 \\
\hline Yes & 14 & 20.0 \\
\hline May be & 10 & 14.3 \\
\hline Total & 70 & 100 \\
\hline \multicolumn{3}{|c|}{ Machine-human relation be enhanced } \\
\hline Strongly disagree & 0 & 0 \\
\hline Disagree & 0 & 0 \\
\hline Neutral & 7 & 10.0 \\
\hline Agree & 48 & 68.6 \\
\hline Strongly agree & 15 & 21.4 \\
\hline Total & 70 & 100 \\
\hline \multicolumn{3}{|c|}{ I support Machine Privacy } \\
\hline Strongly disagree & 0 & 0 \\
\hline Disagree & 0 & 0 \\
\hline Neutral & 9 & 12.9 \\
\hline Agree & 51 & 72.9 \\
\hline Strongly agree & 10 & 14.3 \\
\hline Total & 70 & 100 \\
\hline \multicolumn{3}{|c|}{ Technology singularity is a severe issue } \\
\hline Strongly disagree & 0 & 0 \\
\hline Disagree & 0 & 0 \\
\hline Neutral & 8 & 11.4 \\
\hline Agree & 53 & 75.7 \\
\hline Strongly agree & 9 & 12.9 \\
\hline Total & 70 & 100 \\
\hline \multicolumn{3}{|c|}{ Ethical machines should be designed } \\
\hline Strongly disagree & 0 & 0 \\
\hline Disagree & 0 & 0 \\
\hline Neutral & 1 & 1.4 \\
\hline Agree & 52 & 74.3 \\
\hline Strongly agree & 17 & 24.3 \\
\hline Total & 70 & 100 \\
\hline
\end{tabular}

Table 2 shows the distribution of the perceptions of the respondents as regards ethical considerations of machines. More than half of the participants are of the view that ethical consideration is necessary for machine and automation design. More so, the result show that machine human relationship should be improved. Machine privacy should be instituted. Result reveled that a majority of the participants see technology singularity as a severe issue and then desire for the creation of ethical machines. 


\section{CONCLUSION}

This emerging review has identified key themes and new debates in the literature on major upcoming technologies in the area of service work and knowledge, also accounting for the impacts on society and professions, to give a conclusive perspective on this field of study. The three basic forms of upcoming technology that are captured in this study are artificial intelligence (AI), automation technologies, and robots. The new information and issues that are recurring are the basics for this studies. For instance, studies on their application of technologies have been applied in other sectors including the manufacturing. Novel facts for concerning these technologies outlines the need for more robust moral and ethical considerations of present developments. Vital questions are still left open and needs further investigation based on outcomes of how new technologies are designed, developed and effected in practice, and how employees and humans communicates with machines. Whatever is the case, ethics and rules are of the essence for machines, artificial intelligence and robots.

\section{ReCommendation for Policy and LegisLation}

Many researchers have outlined rules and principles to solve these ethical issues (Luxton 2014; Belloni et al., 2015; Zeng, 2015; Bryson, 2016). These principles and rules are backed by considerations of machines and both human safety. In 2011, some British scientists who were sponsored by the Arts and Humanities Research Council and the Engineering and Physical Research Council proposed some set of ethical codes to designing a robot (Luxton 2014; Ashrafian, 2015; Zeng, 2015; Bryson, 2016). Following these codes, five principles of robotics are outlined.

- $\quad$ Robots are tools with various usage. They should not be created mainly or basically to kill or hurt humans, with exceptions to fostering national security.

- The humans, and not the robots, are to be held responsible. Robots should be built and operated and built in conformity to the available laws and fundamental freedoms and rights, including privacy issues.

- Robots are products. They should be created using processes that gives guarantee to their security and safety.

- Robots are built artefacts. Their make should not be deceptive or designed in ways that exploit users or vulnerable users; rather their machine make must be transparent.

- Legal responsibility of a robot must be attributed to a person (Bryson, 2016). 


\section{REFERENCES}

Ashrafian, H. (2014). AIonAI: a humanitarian law of artificial intelligence and robotics. Science and Engineering Ethics. pp1-12.

Belloni, B, Berger Boissier, O., Bonnet, G., Bourgne, G., Chardel, P. A., Cotton, J. P. (2015). Dealing with ethical conflicts in autonomous agents and multi-agent systems. Papers from the 2015 AAAI Workshop: Artificial Intelligence and Ethics. pp21-7.

Bostrom, N. and Yudkowsky, E. (2011). The ethics of artificial intelligence. Cambridge Handbook of Artificial Intelligence. pp1-20

Bryson, J. J. (2016). Patience is not a virtue: intelligent artefacts and the design of ethical systems. Association for the Advancement of Artificial Intelligence. pp1-18.

Dogan, E., Chatila, R., Chauvier, sS. and Evans, K. (2016). Ethics in the design of automated vehicles: the AVEthics project. Proceedings of the 1st Workshop on Ethics in the Design of Intelligent Agents (EDIA). 2016. pp2-17.

Donepudi, P. K. (2015). Crossing Point of Artificial Intelligence in Cybersecurity. American Journal of Trade and Policy, 2(3), 121-128. https://doi.org/10.18034/ajtp.v2i3.493

Donepudi, P. K. (2018a). AI and Machine Learning in Retail Pharmacy: Systematic Review of Related Literature. ABC Journal of Advanced Research, 7(2), 109-

112. https://doi.org/10.18034/abcjar.v7i2.514

Donepudi, P. K. (2018b). Application of Artificial Intelligence in Automation Industry. Asian Journal of Applied Science and Engineering, 7(1), 7-20. http://doi.org/10.5281/zenodo.4146232

Donepudi, P. K. (2020). Crowdsourced Software Testing: A Timely Opportunity. Engineering International, 8(1), 25-30. https://doi.org/10.18034/ei.v8i1.491

EU. (2017). Robots: Legal Affairs Committee calls for EU-wide rules. EU Press Release. 12 January. Available at: www.europarl.europa.eu/news/en/news-room/20170110IPR57613/robots-legalaffairs-committeecalls-for-eu-wide-rules.

Excell, P. S. and Earnshaw, R. A. (2015). The future of computing - the implications for society of technology forecasting and the Kurzweil singularity. 2015 IEEE International Symposium on Technology in Society (ISTAS) Proceedings. pp1-6

Frude, N. and Jandrić, P. (2015). The intimate machine 30 years on. E-Learning and Digital Media. Vol 12, No 3-4. pp410-24.

Johnson, D. G. (2015). Technology with no human responsibility? Journal of Business Ethics. Vol 127, No 4. pp707-15.

Kinne, E. and Stojanov, G. (2014). Grounding drones' ethical use reasoning. Association for the Advancement of Artificial Intelligence. pp231-5.

Lutz, C. and Tamò, A. (2015). RoboCode ethicists - privacy-friendly robots, an ethical responsibility of engineers? Proceedings of the 2015 ACM SIGCOMM Workshop on Ethics in Networked Systems Research. pp27-8.

Luxton, D. D. (2014). Artificial intelligence in psychological practice: current and future applications and implications. Professional Psychology: Research and Practice. Vol 45, No 5. p332.

Metzler, A. A., Lewis, L. M. and Pope, L. C. (2016). Could robots become authentic companions in nursing care? Nursing Philosophy. Vol 17, No 1. pp36-48.

Michelfelder, D. P. (2011). Dirty hands, speculative minds, and smart machines. Philosophy and Technology. Vol 24, No 1. pp55-68

Reeves, J. (2016). Automatic for the people: the automation of communicative labor. Communication and Critical/ Cultural Studies. Vol 13, No 2. pp150-65.

Russell, S., Hauert, S., Sltman, R. and Veloso, M. (2015). Ethics of artificial intelligence. Nature. Vol 521, No 7553. pp415-18. 
Torras, C. (2015). Social robots: a meeting point between science and fiction. MÈTODE Science Studies Journal. Vol 5, No 0. pp111-15.

Zeng, D. (2015). A letter from the editor: AI ethics: science fiction meets technological reality. IEEE Intelligent Systems. May/June. pp1-5.

$$
--0--
$$

\section{How to cite this article?}

Khan, W., \& Fadziso, T. (2020). Ethical Issues on Utilization of AI, Robotics and Automation Technologies. Asian Journal of Humanity, Art and Literature, 7(2), 79-90. https://doi.org/10.18034/ajhal.v7i2.521 